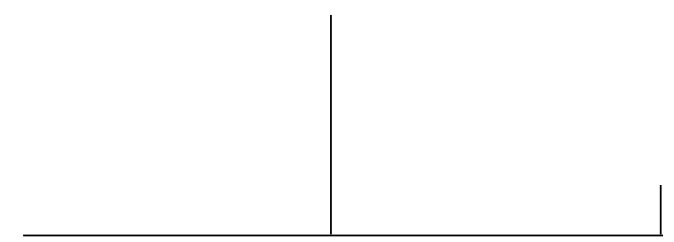

Rev. Latinoam. Psicopat. Fund., São Paulo, v. 15, n. 3, p. 559-574, setembro 2012

\title{
O conflito sexual ${ }^{*}$
}

Egas Moniz

\section{Minhas Senhoras, \\ Meus Senhores,}

Duas grandes forças movimentam e impulsionam a humanidade. Essas forças a que chamaram instintos são a base de toda a nossa actividade física e psíquica. Uma é o instinto da nutrição e da conservação pessoal; outra é o instinto sexual, ou da reprodução.

Nas primeiras idades do homem estas duas forças acham-se confundidas, mas logo que começam a diferenciar-se, o instinto da nutrição e conservação do indivíduo deixa de ter, sobre o organismo psíquico, uma influência apreciável.

$\mathrm{O}$ instinto sexual é, pelo contrário, a base dinâmica da nossa actividade mental.

* Esta conferência proferida em plenário do Congresso Luso-Espanhol das Associações para o Progresso das Ciências em 30/6/1921, foi publicada em Portugal Médico, $3^{\mathrm{a}}$ série, n. 9, p. 385-401, 1921 (N.E.).

Referência do original do texto de Egas Moniz:

Egas Moniz. O conflito sexual. Portugal Médico, Lisboa, v. 3, n. 9, p. 385 -401, 1921. Na revista Cem anos de psicanálise, da qual foi digitalizado o texto de Egas Moniz intitulado $O$ conflito sexual, consta o seguinte na Nota editorial:

"A ortografia foi modernizada em relação aos textos mais antigos, tanto mais que havia nos termos psicanalíticos grafias divergentes conforme os autores ou conforme a época em que os trabalhos foram publicados". 
É o seu grande impulsionador. Orienta-a no campo normal, condiciona-a no terreno patológico.

Estas afirmações que, à primeira vista, podem parecer excessivamente ousadas, são a exacta expressão dos fatos.

Freud foi o primeiro a chamar a atenção para este aspecto do problema sexual, dando-lhe a importância e o valor que merecem e que até então os seus predecessores não lhe tinham atribuído. Os estudos sobre a sexualidade vinham de há muito interessando neurologistas e psiquiatras na interpretação etiológica e patogénica das perversões sexuais.

A obra magistral de Krafft-Ebing, os trabalhos de Moll, de Stanlley Hall e Bleuler, para citar apenas alguns dos mais importantes, foram como que a base sobre a qual Freud se afirmou para a elevada concepção da sua doutrina. Mas foi especialmente a paciente e cuidada observação clínica Breuer duma histérica grave, que conseguiu curar, por um processo novo, e até então não experimentado, que encaminhou o mestre de Viena na orientação do novo processo da psicanálise.

Tratava-se duma rapariga de 21 anos que manifestara, havia tempos, importantes perturbações somáticas e psíquicas.

A doente apresentava paralisia com contratura e anestesia dos membros direitos e algumas vezes também dos esquerdos, perturbação dos movimentos oculares e diminuição da visão, dificuldades em falar, impossibilidade de beber qualquer líquido durante semanas, apesar de sofrer duma sede violenta, crises de confusão mental etc.

Perante este quadro mórbido, duma vasta complexidade, Breuer pretendeu investigar as causas psíquicas que as determinaram. Depois de repetidas observações notou que a doente, quando caía num estado de ausência e de confusão psíquica, tinha por hábito prenunciar algumas palavras sem nexo.

Breuer teve a impressão de que faziam parte dum complexo de representações mentais que, naquele momento, ocupavam o seu espírito. Sujeitou-a então a uma espécie de hipnose e repetiu-lhe as palavras que ouvira como que procurando ajudá-la e ordenar o fio dos pensamentos a que elas andavam ligadas.

Depois de paciente trabalho, chegou à conclusão de que estas expressões se referiam à "situação duma filha junto ao leito do pai doente". E pôde, de averiguação em averiguação, concluir que ela sofria desde a época em que serviu de enfermeira a seu pai, e que os sintomas mórbidos observados não eram mais do que recordações referidas à sua doença e à sua morte.

Seria longo estar a enumerar cada um dos sintomas apresentados pela doente e a procurar as causas especiais que determinam cada um deles. Citemos apenas um. As perturbações visuais encontravam a sua origem no seguinte facto: Uma vez, sentada junto ao leito do pai, pediu-lhe este para ver as horas. Como se es- 
forçasse por conter as lágrimas, estas embaciaram-lhe a vista e só com dificuldade pôde ver os números do relógio.

Este facto, completamente esquecido pela doente, pôde ser lembrado por Breuer, que conseguiu recordar-lho.

Tanto bastou para que essa perturbação desaparecesse. Os outros sintomas foram eliminados da mesma forma por esta espécie de terapêutica catártica ou purificadora, como a princípio a designaram.

Iniciou-se, assim, a prática da psicanálise cuja técnica pouco a pouco se foi aperfeiçoando a que devemos hoje grandes triunfos clínicos.

Seja-me permitido recordar um rápido resumo, um caso pessoal.

Trata-se duma doente de trinta anos que esteve nove anos paralítica dos membros inferiores onde existiam, por fim, fortes retracções. Quando a observei pela primeira vez, apresentava também uma parésia dos membros superiores, dos músculos do tronco, não podendo sentar-se no leito.

Essa doente, que foi observada por vários médicos, nada pôde conseguir da terapêutica instituída. Quando foi entregue ao meu cuidado clínico ensaiei durante dois anos todos os tratamentos psicoterápicos que pude imaginar.

Cheguei a empregar como adjuvante sugestivo violentas correntes farádicas, fazendo o que, mais tarde, durante a guerra, se chamou em linguagem caserneira, o torpedeamento, e que deu o ruidoso incidente da agressão do médico Vincent por um dos doentes electrizados. Apenas obtive melhoras da sua parésia dos membros superiores e dos músculos do tronco, que foram as últimas perturbações a instalar-se.

Foi então que recorri à psicanálise.

De dedução em dedução consegui averiguar que a causa primária do mal se filiava em acontecimentos desagradáveis que muitíssimo a impressionaram alguns anos antes da sua paralisia. A doente como que se esquecera do que lhe dizia respeito, mas auxiliada por mim foi pouco a pouco avigorando a sua memória, recordando particularidades que lhe era penoso exumar do esquecimento a que as tinha votado. A doente atribuía a esses factos, que se tinham passado aos 17 anos, uma importância exagerada. Deles derivaram, a alguns anos de distância, as perturbações a que me referi.

Pois feita esta averiguação e após um pequeno isolamento de 8 dias em que lhe fiz a reeducação da marcha consegui que ela pudesse caminhar, voltando a fazer a vida de movimento de antes da doença.

Foi este facto que me patenteou as vantagens deste processo terapêutico.

Não é propósito meu falar da psicanálise, nem o assunto seria de molde a caber dentro dos limites duma conferência. Se a ele me refiro é porque, sendo um assunto ainda pouco divulgado nos países latinos se liga directamente àquele que me propus tratar. 
Este processo de investigação clínica leva-nos à conclusão de que, quando procuramos investigar as tendências afectivas, especialmente nas psiconeuroses, chegamos quase sempre à conclusão de que elas derivam de perturbações da vida sexual.

Por isso nos referimos ao processo terapêutico da psicanálise que é, ao mesmo tempo, um meio de investigação psicológica. Foi ele que nos veio mostrar a grande importância que tem a sexualidade, quer na vida normal, quer na vida patológica.

Não é este capítulo suficientemente compreendido e estudado no meio médico.

Nas Faculdades de Medicina relega-se a um plano secundário tudo o que se refere ao seu estudo. Daí derivam muitos inconvenientes. Há neuroses e crises psíquicas que não se curam, porque não foram a tempo devidamente interpretadas. Há situações clínicas que se complicam pela falta duma boa orientação em assunto de tão grande importância.

A razão desta deficiência deriva, em grande parte, da repulsa que todos sentem, e os médicos não são excluídos desse natural sentimento, em se ocuparem de questões que se tornam penosas quando são aprofundadas. Devemos vencer esta repugnância natural e enquadrinhar nas suas origens essa força dominadora da vida do homem, cujas perturbações se reflectem imediatamente no campo patológico.

Ainda hoje se recorda o ataque que mereceu um dos meus mais queridos mestres, o malogrado professor dr. Daniel de Matos, o primeiro volume do meu trabalho sobre a "Vida sexual" nos concursos ao professorado da Faculdade de Medicina da Universidade de Coimbra. É que continha doutrinas que feriam mais por serem trazidas à pública discussão do que propriamente pelo que elas representavam de subversivo e ousado.

O estudo das épocas críticas da vida, quer no sexo masculino, quer principalmente no sexo feminino, traçou um novo caminho de investigações a propósito das relações da actividade das glândulas endócrinas com a sexualidade.

De há muito se suspeitava que a glândula tiroideia, por exemplo, funcionava em correlação com as glândulas genitais.

Os velhos autores tinham notado que no período premonitório da puberdade, o pescoço engrossava, e houve até quem fizesse fazer desse facto um sinal da perda da virgindade. Séverin Pineau pretendia que o fio que fosse do lambda à ponta do nariz devia poder sempre circundar o pescoço da mulher virgem. Muitos anos antes já Catulo escrevera:

Nom illam nutrix, orienti luce revisens,

Hesterno collum poterit circundare filo. 
Segundo o poeta latino, a ama, no dia seguinte ao do noivado de Tétis, não pôde cingir-lhe ao pescoço o fio que antes se lhe ajustava. O que tudo prova que, desde remotos tempos, se tinha notado o desenvolvimento da base do pescoço na mulher, em seguida ao iniciamento na vida sexual activa.

Ultimamente, com os progressos da endocrinologia, averiguou-se que a glândula tiroideia, as glândulas suprarrenais, a hipófise e porventura ainda outras, estão em relação com a actividade funcional das glândulas sexuais, de sorte a formar uma cadeia de secreções sinérgicas visando, em parte, ao mesmo fim.

Nas idades críticas, na puberdade e na menopausa, é fácil pôr em evidência estas alterações funcionais que se repercutem no sistema nervoso vegetativo e central e que se exteriorizam por sintomas somáticos e psíquicos.

O hiper e hipofuncionamento destas glândulas, cujo estudo minucioso e verdadeiramente científico não está feito, é, por vezes, ainda discordante.

Assim, nós não podemos enunciar uma fórmula normal em que se mostre a importância de cada um dos factores endocrínicos que entram em jogo. Por outras palavras: ignoramos a relação em que se encontram as hormonas dentro do sangue normal.

Estou mesmo convencido de que outros elementos químicos entrarão em acção ao lado dos produtos de secreções endocrínicas vindas de outros elementos celulares. Não pudemos, consequentemente, dizer ao certo quais são os elementos excitadores ou frenadores que vão actuar no sistema nervoso nas épocas críticas.

Sabemos, contudo, duma maneira geral, que no período da puberdade e na crise menopáusica há glândulas que ou entram numa superactividade funcional ou amortecem a sua vida secretória. Quando se invertem consideravelmente estas actividades, ou quando se exageram, mesmo na sua orientação normal, observam-se crises violentas com reflexo na actividade psíquica, quer ligada à função sexual, quer desvirtuada ou transfigurada em sentido diferente.

Estas secreções, embora não sejam as únicas determinantes da conduta sexual, representam um factor importantíssimo, e a endocrinologia veio desvendar novos horizontes àqueles que ligam a este problema a importância que este merece.

A vida orgânica e a vida psíquica andam, assim, em torno da função sexual.

Muitas perturbações mentais nas neuroses e até nas psicoses dependem das alterações da normalidade sexual.

O problema é muito mais vasto do que pode parecer à primeira vista. Não depende somente dos factores internos. A sexualidade modifica-se e deforma-se por influências exteriores.

A luta entre a necessidade da satisfação da líbido e as oposições de toda ordem vindas do meio exterior, é a mais grave perturbação da vida do indivíduo e 
aquela que mais se repercute na esfera mental. Esse conflito surge nas primeiras idades, com o alvorecer das actividades cerebrais e perde-se no ocaso da existência, mesmo depois de aniquiladas as funções reprodutoras.

A líbido é, na sua maior parte, a consequência da actividade mais ou menos complexa das glândulas endócrinas e ainda de outros factores orgânicos; orienta-se em sentido normal ou patológico, alcança caracteres especiais, consoante as determinantes externas que sobre ela impendem.

A idade infantil é a idade formadora da líbido, Bleuler, numa denominação bem germânica, apelidou de pansexualismo a doutrina do instinto sexual considerada como a dinâmica de toda a actividade psíquica.

As anomalias e os desvios que podem produzir-se na marcha regular das tendências sexuais, são outras tantas origens de estados patológicos futuros.

Os pequenos traumas morais que nessa época conseguem perturbar o seguimento normal do desenvolvimento erótico, são as causas eficientes das futuras neuroses que a escola de Viena quer encontrar lado a lado das perversões sexuais.

A existência da sexualidade infantil é um facto inteiramente demonstrado, e, contudo, durante muito tempo se defendeu a doutrina de que o instinto sexual apenas aparecia com o despontar da puberdade. Julgou-se até que, salvas raríssimas excepções, se dava nessa época a explosão súbita do desejo sexual como se ele surgisse sem preparação mais ou menos intensas através da idade infantil e prepúbere. Sabia-se, é certo, que algumas crianças podem apresentar a anomalia de uma grande precocidade sexual, mas considerava-se o facto sem importância e ninguém antes de Freud pensou em fazer o estudo psicológico das tendências infantis no sentido da sexualidade.

Hoje sabemos que essa função está ligada ao funcionamento de determinadas glândulas que não surgem de um dia para o outro no estado de completa actividade, antes se vão desenvolvendo pouco a pouco até a transformação apropriada. Por isso era de esperar que, ao lado desse desenvolvimento, se fossem firmando as tendências sexuais.

Como, porém, nas crianças normais, nada as denuncia nitidamente, e como, por outro lado, nos adultos são raras as reminiscências dos factos sexuais infantis, nunca se deu ao assunto a atenção que ele merecia.

A amnésia infantil esconde tudo o que respeita à sexualidade. Esta amnésia distancia-se fundamentalmente do esquecimento banal dos factos insignificantes da vida. Pelo contrário, aproxima-se muito da amnésia que observamos nas neuroses.

O mecanismo da sua produção é inteiramente similar.

A sexualidade surge no homem com as primeiras manifestações da vida extrauterina, tendendo a satisfazer-se duma maneira difusa, sem se localizar às re- 
giões genitais. A líbido depende, nessa época, especialmente da excitação de algumas regiões da pele ou das mucosas que circunstâncias especiais tornam mais sensíveis. O fim sexual infantil consiste em provocar uma certa satisfação pela excitação dessas zonas erógenas. Estas tanto podem ser os órgãos sexuais externos, como a região anal, os lábios, e até mesmo certas porções de pele. Freud considera como a primeira manifestação da sexualidade a sucção do mamilo no aleitamento. Em seguida, generaliza-se a sucção do dedo ou dum objecto qualquer, o que muitas vezes determina um sono tranquilo. Nessa fase é difícil precisar o que pertence ao prazer da nutrição e o que significa satisfação erótica, mesmo no sentido lato que pretendem atribuir-lhe.

Confundem-se esses dois instintos no mesmo objectivo; mas é bom acentuar que, embora nos pareça exagerado, o conceito freudiano representa alguma coisa de verdade que factos subsequentes vêm pôr mais a claro.

Assim, as excitações de certas regiões podem explicar a evolução e a objectivação da líbido. Basta citar a influência que a retenção das fezes pode determinar na região ano-retal. As crianças multiplicam muitas vezes as suas evacuações para produzirem uma espécie de prazer local; ou retêm-nas voluntariamente, a fim de conseguirem, pela sua acumulação, uma sensação mais violenta no acto da evacuação. Outras vezes o prazer que provocam à criança as excitações da zona uretro-vesical levam-na a provocar micções repetidas em que há inquestionavelmente uma certa satisfação de ordem genésica. Nessa época aparecem as pseudoincontinências urinárias de que os clínicos de há muito deram conta e que têm a etiologia que acabamos de apontar. Alguns casos dessa natureza nos têm passado pelas mãos: micções aparentemente involuntárias em vigília e involuntárias, de facto, durante o sono.

Temos registrado alguns desses episódios sobretudo em crianças do sexo masculino, em que essas crises de incontinência acompanham certos actos violentos, em lutas com os companheiros, em correrias etc. Outras têm as suas perdas urinárias durante a noite, muitas vezes com sonhos em que predomina, como facto dominante, o prazer da emissão de urina. Isso prolonga-se, por vezes, até muito tarde. Conheço casos de 12 a 13 anos. Estas perdas são como que e esboço duma verdadeira polução. Alguns as denominam poluções urinárias.

Ao mesmo tempo aparecem manobras mais complexas provocadas por determinados factores, tais como a irritação por falta de higiéne, ou por excessivos cuidados de limpeza, estimulações pelos vermes intestinais excitações criminosas de estranhos etc., que são por vezes a causa da masturbação precoce.

Há um período em que todos esses fenómenos se produzem naturalmente, sem intervenção alguma contentiva. A criança patenteia-os com maior indiferença. Considera-os tão naturais como a alimentação. 
Em seguida há como que uma renúncia progressiva a essas práticas, devido principalmente às influências educativas. Formam-se então as primeiras potências psíquicas, inibitórias da sexualidade: a vergonha, as pressões morais e religiosas. É o início do conflito. Dum lado está o desejo da satisfação, embora vaga e imprecisa da sexualidade; do outro lado os factores de ordem elevada que tendem a reprimi-lo.

Quando surgem circunstâncias exteriores perturbadoras, tais como iniciações sexuais provocadas quer por adultos quer por outras crianças, produzem-se os primeiros traumas afectivos que passam despercebidos aos educadores e que, mais de que quaisquer outros, a criança procura esquecer.

A vida sentimental infantil é muito mais intensa e muito mais cheia de episódios de que a do adulto. É nessa idade que as aventuras amorosas homossexuais ou heterossexuais se sucedem com intensidade.

A sexualidade dessa época recorda a cera mole a que o acaso dos acontecimentos pode imprimir todas as formas possíveis.

A criança só mais tarde concretiza o objecto de instinto sexual. É o período em que começa a esboçar-se a atracção sentimental e sexual por pessoas do sexo oposto. À primeira sensação imprecisa, sem determinação nem zonas especializadas, sucede a orientação da procura do objecto sexual. Inicialmente o amor brutal da criança pela mãe, com a sua satisfação nas carícias que lhe são tributadas, representa uma forma precoce dessa exteriorização.

É um facto averiguado que a criança, em geral, se sente mais atraída pelo progenitor do sexo oposto. O filho aproxima-se mais da mãe, ao passo que a filha é mais amiga do pai. Esta atracção é, em geral, acompanhada de ciúme por vezes muito intenso dos outros concorrentes sentimentais, incluindo o pai ou a mãe, consoante o sexo da criança. Esse sentimento torna-se, por vezes, tão intenso, que a criança chega a desejar o desaparecimento dos seus concorrentes afectivos, o próprio pai ou a própria mãe, para a obtenção de um exclusivismo sentimental que não quer que seja compartilhado.

Só quando se aproxima a puberdade, inteiramente despida desta imoralidade infantil, é que esta espécie de sentimentos fundamentalmente sexuais, se transformam, por sublimação ideativa e educativa, na verdadeira dedicação filial.

Nas primeiras idades a exteriorização do sentimento sexual não se limita a este aspecto afectivo, desce a concretizações mais definidas. Assim a criança experimenta prazer em contemplar a nudez das outras crianças (forma activa) e outras vezes procura mostrar a sua própria nudez (forma passiva). É por essa época que procuram dominar e maltratar outras crianças ou animais, o que pode chegar ao extremo duma crueldade feroz, cuja precocidade é um sinal característico de ulteriores exigências genésicas. São manifestações sadistas embrionárias como o são de manifestações masoquistas em esboço, os desejos, da 


\section{CLÁSSICOS DA}

PSICOPATOLOGIA

crueldade exercida pelos outros. A primeira é mais vulgar nas crianças do sexo masculino; a segunda nas do sexo feminino.

Como se sabe, o homem mais normal tem tendências sádicas, ao passo que a mulher mais equilibrada apresenta tendências masoquistas exteriorizadas principalmente na natural submissão ao homem, produto da educação que avigora uma predisposição instintiva.

Depois vêm as conversas infantis sobre o nascimento, o interrogatório. Por vezes ardiloso, feito aos pais e aos conhecidos. A criança reconhece, a breve trecho, que há a preocupação de lhe ocultar tudo o que diz respeito a esse assunto.

É o período das interpretações bizarras da sexualidade.

Ao mesmo tempo manifestam-se as primeiras formas de excitação genital geral, tais como as que derivam dos movimentos rítmicos que actuam sobre a pele, sobre a sensibilidade profunda e, mais tarde, sobre os órgãos sexuais, embora de uma maneira ainda vaga e imprecisa. Os exercícios musculares violentos vêm trazer inesperadas luzes à curiosidade da criança. As emoções afectivas intensas são igualmente poderosos excitadores. Muitas vezes a emoção do primeiro exame é o despertador de ignoradas sensações.

O próprio trabalho intelectual as pode originar. A prática de certos actos que a criança sabe que são incorrectos ou quase criminosos traz-lhe íntimos desgostos. Procura evitá-los. Por vezes não o consegue, mas nem por isso deixa de estar em luta com a sua personalidade ética.

Sente sobre si a influência da educação e do meio social e religioso em que vive. São essas aquisições psíquicas as forças repressivas que recalcam dentro do inconsciente os factos que a incomodam.

A criança obtém assim o seu esquecimento. Por esse processo alcançam a tranquilidade. É como se não existissem. Desde que ultrapassam os umbrais da consciência ficam fora da crítica individual.

São essas forças que permanecem na sombra, as que principalmente nos governam, mas sempre de uma maneira anónima e dissimulada.

Para Freud o inconsciente é o real psíquico; mas esta realidade interna é dificilmente reconhecível.

Vivemos na ignorância quase absoluta de tudo o que se passa dentro de nós. O inconsciente é o mais; o consciente é o menos na nossa vida psíquica. Os fenómenos mentais mais complexos podem produzir-se sem ultrapassar o limiar do autoconhecimento.

O jogo das imagens ou impressões sensoriais da experiência quotidiana, a mecânica das emoções, a elaboração das aptidões motoras, compreendem a imensa maioria das nossas ideias e sentimentos. Vão-se armazenando, desde os primeiros momentos do desenvolvimento infantil, no domínio do inconsciente, e aí permanecem intactos, sem se enfraquecerem, com todo o seu poder de acção sobre 
o organismo. São eles que presidem duma maneira eficaz e contínua ao determinismo da nossa vida consciente.

Há gradações entre estes dois estados.

Assim, há dentro do psiquismo inconsciente elementos em número infinito que não podem adquirir a forma consciente. É o inconsciente propriamente dito.

Além destes, há outros elementos, em muito menor número, susceptíveis de se tornarem conscientes. Constituem o pré-consciente. Os primeiros formam o sistema que inicialmente se fixou e são as forças directrizes do pensamento e da acção, os instintos e as tendências mais poderosas do indivíduo, a base do dinamismo da nossa vida psíquica. Os segundos formam como que a fronteira entre o consciente e o inconsciente e constituem todos os conhecidos fenómenos de distracção, de inspiração, de devaneio, de sonho, que são as revelações subjectivas da realidade interna ignorada. Por isso lhes chamaram os mensageiros reais do psíquico, os reflexos ou os ecos do inconsciente.

Estes segundos elementos, como os primeiros, forças psíquicas actuantes no meio inconsciente, são os únicos que podemos fazer aflorar ao nosso conhecimento. Para o conseguirmos, temos de utilizar os processos da psicanálise. E tanto os resultados a que eles conduzem são exactos que as observações psicológicas directas da vida infantil mostram a concordância dos resultados.

Muitas vezes estas forças deformam-se disfarçam-se e aparecem no limiar da consciência em formações psíquicas duradoiras que são a base das psiconeuroses. Para as descobrir é preciso, por vezes, um trabalho pacientíssimo de que somente a psicanálise consegue triunfar. $\mathrm{E}$ isso ainda se torna mais difícil quando as novas formações, já depois de desfiguradas, são de novo recalcadas para o inconsciente, aparecendo em seguida numa nova reprodução e assim sucessivamente.

Estas alterações dos complexos iniciais encadeiam-se numa emaranhada trama afectiva, acabando por se fixarem definitivamente adentro do inconsciente. São elas as bases das fobias, das obsessões, dos delírios, das alucinações, das impulsões, das dissociações psíquicas, dos estados hipnoides, oníricos, crepusculares.

$\mathrm{Na}$ vida usual é fácil descobrir complexos sentimentais e sexuais em factos que não passam os limites da normalidade. A religiosidade, a coqueteria, a dedicação pelos animais, o desejo de sacrifício pelos desprotegidos da fortuna, o prazer de relato de escândalos etc., são apenas representações de complexos normais: a ternura conjugal e o amor sexual.

São ainda os complexos que permanecem dentro do inconsciente, especialmente os que foram mais vivamente repelidos, que orientam muitas tendências amorosas futuras. É assim que a objectivação das primeiras inclinações pelos 
pais, irmãos, irmãs etc., podem determinar mais tarde a escolha de pessoas que recordem reminiscências dessas primitivas atracções.

As próprias perversões sexuais encontram muitas vezes a sua origem em factos da vida infantil. Neste campo a escola de Freud exagera, em meu entender, as suas conclusões quando pretendem explicar a etiologia das psiconeuroses pela repressão das perversões sexuais. Quantas vezes elas se associam!

A perversão sexual encontra a sua origem no período da concretização da líbido, no conflito estabelecido entre a apetência sexual insatisfeita e as pressões exercidas sobre a criança por diversas circunstâncias e acções vindas do meio exterior. Estas são variáveis de raça para raça, de país para país, de clima para clima. Conservam, porém, em quase todos os povos civilizados uma base que é constante, pondo diques mais ou menos fortes à expansão natural das actividades genésicas. Daí resulta um conflito permanente entre o indivíduo e o meio, conflito que não se limita à idade infantil, pois atravessa a vida inteira. Dum lado o impulso imperioso que resulta do modo de ser orgânico de cada um, do outro lado as forças sociais que se opõem à sua efectivação. No adulto, além de todos os obstáculos de ordem elevada, há ainda o receio das consequências que podem resultar da livre expansão do impulso libidinoso. E se nos normais a luta acaba por um acordo que não brigue com as condições individuais e sociais, em outros a luta permanece acesa durante largo período, acabando por se dar o desequilíbrio que deixa sempre ferido o indivíduo, quer vença quer seja vencido. Esta noção que é necessário pôr em evidência na apresentação da etiologia das neuroses, não é uma noção da medicina moderna. Até a palavra histeria o denuncia! A doutrina sexual está aí bem vincada e vem dos primeiros tempos da medicina. Já Platão dizia que os ataques histéricos provinham da matriz, "animal que deseja ardentemente gerar filhos". Quando fica muito tempo estéril após a puberdade, acrescenta, indigna-se, percorre todo o organismo para a respiração e lança o corpo em perigos extremos.

E se é certo que o útero se não desloca, giram por ele as secreções internas dos ovários e glândulas associadas.

O conceito do filósofo tem, porém, de ser generalizado. Não são apenas mulheres que ficam estéreis por muito tempo em seguida à puberdade, que apresentam os sintomas convulsivos e psíquicos do proteico mal. No período infantil, durante a puberdade, na época sexual, na menopausa, e nas idades pré-senil e senil, eles podem aparecer.

Por outro lado, o conflito sexual não é pertença exclusiva do sexo feminino. Também se encontra no homem. E se é mais vulgar e mais intenso na mulher, é porque as condições orgânicas que lhe são peculiares e as pressões sociais, muito mais severas para ela, tornam mais difícil no sexo feminino a sua solução. 
O resultado final de não cedência do indivíduo aos naturais impulsos sexuais, a princípio vagos e imprecisos e mais tarde nitidamente concretizados, nem sempre se acomoda à passividade resignada dos que não puderam objectivar as suas tendências.

As neuroses não encontram apenas a sua origem nos traumas sexuais da infância, nos reliquats perdidos no inconsciente dos conflitos das primeiras idades e que actuam como causas ignoradas das futuras perturbações psíquicas. A concepção freudiana tem de ser generalizada.

É muitas vezes em plena puberdade, e sobretudo na mulher, ao embate das fortes desilusões das primeiras preferências ou no desespero da aproximação da idade menopáusica que essas perturbações surgem sem a complicada forma que expusemos, mas com a mesma origem e por um mecanismo similar. É possível, e assim o temos reconhecido algumas vezes, que os acidentes da vida genésica infantil tenham também a sua quota parte de responsabilidade em alguns desses casos, mas noutros têm uma importância mínima.

A histeria é o tipo mais vulgar e sobretudo mais compreensível destas perturbações. Ora há casos de histeria tardia, e até de histeria em idade avançada, em que é fácil descobrir causas de foro sexual, sem intervenção do que possa ter sucedido na infância, porque os factos de que derivaram as perturbações constatadas são de recente data.

O que dizemos da histeria podemos igualmente afirmá-lo, embora sem o mesmo exclusivismo, no que discordamos das afirmações de Freud, dos estados melancólicos, obsessivos, fóbicos, da demência precoce etc.

$\mathrm{Na}$ quase totalidade desses casos se a etiologia não está apenas adstrita ao conflito sexual, pelo menos encontra em perturbações desta ordem um elemento patogénico de acentuada importância. Temo-lo reconhecido muitas vezes, quer provocando explicações directas conscientes, quer recorrendo a investigações psicanalíticas. O conflito estabelece-se sob variadíssimos aspectos e não só nos casos da insaciedade sexual. Há pequenas particularidades, tendências e predileções que o transportam para outros campos. Eu poderia, neste momento, fazer uma larga exemplificação de que afirmo; mas nem me comporta a exiguidade do tempo, nem o fim que tive em vista.

Basta que lhes resuma em algumas palavras um caso bem concludente: uma senhora de 25 anos, casada, com um filho, apresentava um forte acesso de ansiedade melancólica, o primeiro que teve, e que a trazia num estado de excitação dolorosa, com repetidas crises de choro e grande mal-estar.

Tudo o que representar emoção tem de ser tomado em linha de conta. Pois anda ligado às associações que jogam directamente com o complexo procurado e cuja existência se denuncia, no limiar da consciência, por uma maior perturbação. 
Esta é máxima no momento em que ele começa a surgir, e termina-se por uma explosão efectiva quando triunfando da resistência, é posto inteiramente a claro.

Este processo é menos moroso do que o dos sonhos, mas não é tão moroso como porventura pode deduzir-se do que acabo de expor. Toda esta investigação psicológica carece de não ser precipitada; tem que se caminhar vagarosamente a passos seguros.

Há, ainda, um outro processo psicanalítico: o da investigação experimental das associações de ideias. É o preconizado pela escola de Zurich e tem vantagens e desvantagens sobre os anteriores.

Consiste no seguinte:

Quando se apresenta a um indivíduo em estado hipnótico uma palavra qualquer, e quando se convida a responder imediatamente com outra palavra, provoca-se um reflexo cerebral associativo que supõe, entre outros mecanismos, uma ligação sensorial e motora das duas palavras: a indutora e a da reacção.

O estudo da palavra-reacção em si e as circunstâncias que acompanham ou seguem a sua emissão, tais como repetições, associações com outras palavras ou frases, estado emotivo, gestos e, sobretudo, o tempo de reacção medido ao cronógrafo eléctrico são elementos preciosos de dedução na descoberta de complexo fundamental.

Sempre que qualquer palavra evoca associações que lhe estão ligadas, dão-se perturbações na emissão da palavra-reacção, salientando-se entre todas, o alongamento de tempo verificado pelo cronógrafo.

A técnica deste processo é bastante complexa, pois há muitos cuidados a tomar para se não ser induzido em erro.

$\mathrm{Na}$ doente a que há pouco me referi apenas apliquei os dois primeiros processos. Os seus resultados foram concludentes. É esta a sua melhor defesa. Com efeito, foi devido a eles que consegui obter uma cura quando outros processos terapêuticos tinham falhado. Este caso mostra ainda à evidência como tardiamente, e numa pessoa aparentemente saciada sexualmente, se pôde instalar uma neurose com uma base claramente sexual.

Devo notar que a doente ignorava que há mulheres que não chegam a sentir a líbido sexual, reputando, por isso, extremamente grave a sua situação de esposa incompleta e única como ela se denominava.

Já os casos a que atrás me referi demonstram que as perturbações iniciais podem dar-se fora da idade infantil. Algumas andam mesmo em torno da crise menopáusica e outras ainda mais tarde.

A importância desta etiologia não está, como defende Freud, apenas adstrita à vida infantil. Aparece, e sob várias modalidades, através de todas as idades.

Na época infantil tem igual importância tanto num como neutro sexo, talvez mesmo mais no sexo masculino. Depois é muito mais importante na mulher do que 
no homem. Isso deriva da diferença das condições sociais dos dois sexos. O conflito sexual tende sempre para uma fácil solução no homem. Pelo menos há sempre a possibilidade de uma solução aproximada. Mas na mulher o caso é bem diverso. Não são só os deveres sociais que actuam sobre ela; não são apenas as imposições religiosas que na mulher têm, geralmente, maior força; não são ainda as circunstâncias educativas e as influências morais que, sob múltiplos aspectos, sobre ela actuam. Há também independentemente de todo este conflito psíquico, as consequências orgânicas do acto: a perda da virgindade e a maternidade.

Há quem pense que esses conflitos se poderiam extinguir com profundas reformas sociais. Não o acredito. A maior parte dessas lutas íntimas continuariam a existir e as desprotegidas de atractivos talvez ainda tivessem, após uma radical transformação no nosso meio de ser social, mais fundos conflitos.

O caso que apresentei mostra que, mesmo dando-se todas as condições para a saciedade sexual, o conflito pode ainda parecer. Algumas reformas sociais poderiam, contudo, melhorar as condições e diminuir a sua frequência. O problema é, porém, tão vasto e tão complexo que não ouso sequer enunciá-lo. Não cabe no limite das minhas forças. Contento-me em acentuar que é preciso dar uma atenção e cuidados especiais à educação infantil sob o aspecto sexual. Torna-se necessário orientar as crianças no sentido das afeições normais evitando excitações, espectáculos ou insinuações que possam encaminhá-las no sentido da precocidade ou das perversões sexuais.

Mas, por mais que se faça, não conseguiremos evitar todos os conflitos. Eles podem dar-se sem que possam ser percebidos através dos pequenos acontecimentos a que só a criança dá uma grande importância. E, se alguém pretender investigá-los, fará, em geral, obra contraproducente, indo despertar tendências ignoradas.

A idade que decorre entre os quatro e nove anos é, por certo, a mais importante. $\mathrm{O}$ cérebro infantil vinca nessa idade, mais do que qualquer outra, a passagem de tudo o que a impressiona. E os acontecimentos que se referem à sexualidade são, entre todos, os que maiores impressões deixam e os que mais complicações trazem.

A puberdade é o terminus dum período de preparação, em que as actividades psíquicas e somáticas da criança estiveram em contínua laboração.

Minhas Senhoras,

Meus Senhores,

A importância e o interesse que esse assunto tem despertado demonstra-se pela divulgação que a psicanálise, e consequentemente o estudo da sexualidade, está despertando em todo o mundo, nomeadamente nos países da Europa e na América do Norte, onde as publicações e as revistas sobre o assunto se multiplicam. 
O sistema ultrapassou mesmo os limites para que foi criado, alcançando as avantajadas proporções dum novo sistema filosófico que não se limita apenas às aplicações terapêuticas ou às investigações etiológicas das neuroses.

É, por exemplo, um elemento muito importante a considerar como processo de investigação na psicologia normal. Constitui um método geral de exploração psíquica, fecundíssimo em resultados.

Foi especialmente pelo valor que veio dar ao inconsciente que chamou atenção dos psicólogos.

Alguns lhe chamam hoje, como Hitschmann, a metapsicologia.

Nos domínios da arte tem-se procurado utilizar os seus métodos na análise das obras artísticas segundo a psicologia dos seus autores. Por outras palavras: tem-se conseguido explicar o mecanismo da composição duma obra literária, dum quadro, duma estátua, dum trecho sinfónico, através de gestos, tendências e aspirações daqueles que os criaram. Tem-se ido até ao estudo do seu desenvolvimento psicológico, reconstituindo-se a sua génese pela interpretação dos incidentes da história da sua vida.

Mais do que isso: a psicanálise aspira a estudar completamente a própria emoção artística. Rompendo o invólucro demasiadamente acanhado da psicologia tradicional, penetra mais fundo. Assim, na apreciação duma obra literária, ela não se contenta em julgá-la apenas através dos pontos comuns do estilo, da inspiração, da forma etc.; procura dar-nos as razões da nossa invencível admiração pelo talento ou pelo génio.

Na filosofia também tem intervindo, estudando os motivos subjectivos e individuais que determinam a formação das diversas doutrinas e sistemas.

Na sociologia vai mais longe. Pretende oferecer soluções práticas, sobretudo no que respeita à psicologia sexual. Por certo tem-se exagerado estas aplicações, tem-se mesmo deformado a doutrina aventurando-a em alguns devaneios; mas quando sóbria e cuidadosamente conduzidos, podem os processos psicanalíticos, mesmo nesse campo, prestar grandes serviços.

Os primeiros estudos de Freud conduziram-no modestamente a combater ou a prevenir os efeitos do onanísmo, da excitação sexual insatisfeita ou das práticas sexuais irregulares. Mas a sua obra excedeu avantajadamente os seus primitivos e modestos propósitos. Hoje não visa apenas a regularizar as funções genitais no seu aspecto físico.

Muitos neuropatas não se curam completamente por meio desta rudimentar higiéne. Foi o que sucedeu com a minha doente do último caso apresentado.

A doutrina psicanalítica pretende formar o carácter do homem nos seus traços primordiais. À energia bem orientada no sentido sexual anda ligada, em perfeito paralelismo, a energia de todas as funções morais práticas. 
É estudando estas dependências e associações que a psicanálise quer fazer mais um longo e triunfal caminho.

\section{Minhas Senhoras,}

Meus Senhores,

Talvez se julgue pouco apropriada para este lugar a exposição que procurei fazer deste interessante capítulo da Ciência Médica. Dada, porém, a sua importância e vantagem da sua divulgação, ouso rematar as minhas considerações afirmando que a ignorância deste assunto representa uma lacuna nos nossos programas de ensino médico.

E concluo, para minha inteira justificação, com as palavras de Tardieu:

"Le ministère sacré du médecin, en l'obligeant à tout voir, lui permet aussi de tout dire".

Disse.

\section{Egas Moniz}

António Caetano de Abreu Freire Egas Moniz nasceu em Avanca (Portugal) em 29 de novembro de 1874 e faleceu em Lisboa (Portugal) em 13 de dezembro de 1955. Prêmio Nobel de Fisiologia em 1949 por seus estudos sobre a leucotomia pré-frontal no tratamento de certas doenças mentais (psicocirurgia), nomeadamente a esquizofrenia. Personagem ímpar da história portuguesa, foi um eminente investigador, médico, Professor universitário em Coimbra e em Lisboa, diplomata enquanto Embaixador em Madrid e político no cargo de Ministro dos Negócios Estrangeiros em 1917. 